\title{
Unified Patient Information System for Iraqi Hospitals
}

\author{
Mohammad Khalaf \\ Rahim \\ Assistant Lecturer \\ University of Kufa-Iraq
}

\begin{abstract}
Because of the health conditions experienced by the country, especially in the last three decades in Iraq Caused by various conditions, including the difficult political crises that have passed represented and pass the country's and other economic conditions and environmental and the absence of quality control, especially in the period following the year 2003, Which invited us to think in an attempt to reduce the incidence of certain diseases by facilitating the linking causes their causes That's where recording patient information in a unified database After comparing it with the circumstances that accompanied the emergence of those conditions, Researchers can identify the problem clearly linked through the circumstances that have occurred in these specific dates periods. In this system, using program visual .Net as a front for entering of data that will be stored in the database for the purpose of retrieval through a program that works on the web site when you need to retrieve it. The proposed system overcomes the problems related to retrieve and find particular information, waste of effort and time, inoculation details of patient is difficult to make as input costs requirements and paperwork burdens is involved and to collect from various registers, probability of error in manual calculations, and provides the support the researchers to take a decision.
\end{abstract}

\section{Keywords}

Patient Information System for Iraqi Hospital (PISIH), Electronic Patient Record (EPR), Electronic Health Record (EHR).

\section{INTRODUCTION}

Medical applications of computer science started at 1950, then consequently come Medical computer science, Medical information science, biomedical computing, Medical informatics and Health or healthcare informatics.Medical information systems care to register for storing patient data in addition to the exchange of this information between medical information systems in various systems Where the medical community is looking to set up an account for the patient's entire medical history includes different health institutions and doctors treating different time periods and that improve the general quality of health for accurate remedial decisions.

The benefits of electronic medical records reduce reliance on paper records which is damaged, you need to places to be stored in addition to the difficulty of retrieving information

All computer-based systems such as Hospital Management System, Patient information system, Patient monitoring system,....etc based in improving the health situation to reduce future disease infection and clinical errors, especially with regard deadly diseases and chronic ones. A major Health problems nowadays suffered by Iraqi citizens as a result of wars and the difficult economic conditions in recent decades of the most important challenges faced with Iraqi society and affecting the most important aspect of the life of Iraqi citizen, but it is the health aspect. Computer uses in medical fields associated with storage, processing, analysis and commutation of information e.g. Mathematics, library science, information systems, communication technology.

So far, there are no accurate statistics, for example, the number of people with a particular disease, age, address and date of injury and their relationship to their causes such as food, contaminated devices radiation such as communications equipment, pollution of drinking water, the radiation caused by the remnants of war, sand storms, the impact of the emission of toxic gases from industrial cities or vehicle exhaust.

PISIH Contains a patients personal information, a patient's medical history, diagnoses, medicines, test reagents, surgical equipment, bandages, allergies, radiology images, name of overall (Civil and government) hospitals in Iraq [1], laboratory and test results. All patients might disagree to show their personal and health status information that will almost certainly vary from country to country, region to region and organization to organization, person to person; so the name of patient had been removed from the final report that will finally submit to the researchers due to overcome this problem, some of the researches that will discuss some of the methods for patient's authentication. Other problem, physicians directly collect patient information in the time of consultation.

There are some systems that began in the use by health centers in recent years, such as antenatal care system tables vaccinations for children, which is one of the signs of the boot to adopt other new applicable systems in this field.

\section{LITERATURE SURVEY}

Studying of all the aspects of EPR is not possible due to the time limitation and enormous researches in this field. The data in our system is designed to serve the researchers in medical fields and own by ministry of health unlike The data in the Electronic Medical Record that legal record of health status to the patient during their encounter at the care delivery organization and is owned by it, while Electronic Health Record is owned by the patient and has patient input and access that spans episodes of care across multiple CDOs within a community, region, or state (or in some countries, the entire country), The EHR in the United States will ride on the proposed National Health Information Network (NHIN) [2]. In [3] developing interoperable IT solutions for various segments of today's healthcare systems, and develops patient centered process ontology.

The new system has been designed for medical practitioner/physician to keep track of all patients' medical record/ information, this system undertakes a long processes and tedium work involved in tracing and retrieving a patient's record that can provide required records on time [4]. By making medical history data available during emergency care 
[5] first aid for patient will be easier. In [6] "Hospital Information Systems supported the clinical work of health care employees by adapting the software to user requirements, improving its functionality continuously and avoid errors and stress reactions as well as the costs associated herewith". In [7] framework is applied in a case study of a large general hospital in the Netherlands was found that the use of Information System in this hospital did not develop according to the needs and developments in Hospital organization over the past decade. some other papers like [8] histological segments to the material are the object of registration and related information measure the subset of the images in which no need for calculating function derivatives, while in [9] construct refined item banks made existing clinical research and practice. Another research paper [10] was developing healthcare system for collecting patient information then reports it as a result. In [11] built data base for patient medical electronic report accessing remotely by patient and administrator.Proposed system in [12] assists clinicians to manage interruptions of information and manage itscommunication and coordination, coordination of events and activities are also used in [13], [14].Some Motivating has been discussed for making staffs relay on Hospital Information System while some Hindering Forces stand as barriers [15], [16].Contextual authorizations use in [17] as environmental information to authorize the access of user/patient to an resource,also in [18],[19],[20],[21] variousCollaboration Pattern and Collaboration policies for authorization control have been introduced.A new method called community-based implementation used in [22] to make consumer manage for Personal Health Records. Improve patient service delivery by design and team effort between people and technical solution in [23].

There are a lot of research papers and new system have been developed in this field with various purpose, all these papers works under health care researches.

\section{SYSTEM DESIGN \& CASE STUDY}

\subsection{Overview of System Design}

Figure 1 shows the major aspects that consist of the proposed system web based program allow access to evidence-based tools that providers can use to make decisions about a patient's care, the system also have Normalized database, Prevention of duplication login, Design patterns, Exception handling, and Hospital-side validations.

Database is built to collect clinical data by establishing common terminology that can be inclusive of patients' information all hospitals in Iraq. The method in this system is connecting systems with securely process by entering in a username and a password accesses the MY-SQL database located on the server for protecting the clinical information.

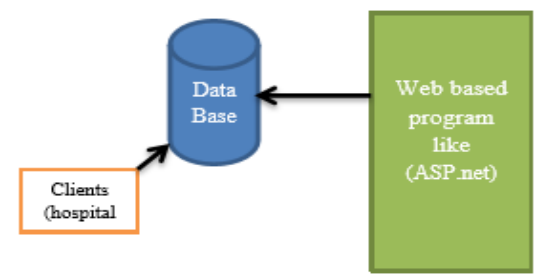

Fig 1: General View of Proposed System

The demonstrating of the system in figure 1 , it involves significant technical, political, social hurdles. Figure 2 shows the structure of the proposed system:

\subsection{Structural \& Database Design}

The database contains hospitals in Iraq and patients' information's forms. There are two tables used in our system one for hospital information and patient table as in figure 3, linking tables together will be with foreign keys.

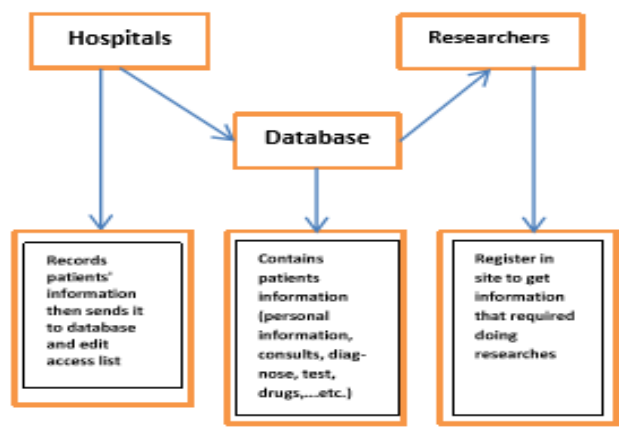

Fig 2: Participants Method

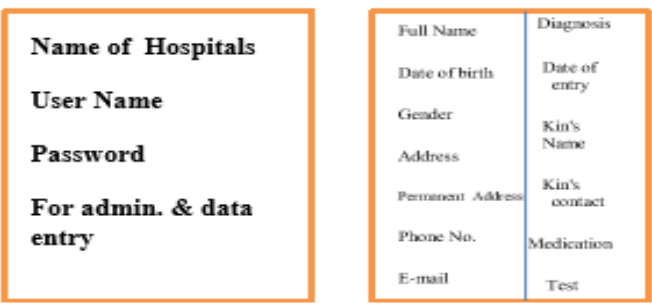

Fig 3: A- Hospital Information B-Patient Information

\subsection{Case Study}

The simple case study depends on sample from Iraqi physicians and researchers interested in medical fields to promote the feasibility of proposed system, result shown in table 1 and 2 .

Table 1: Physicians Opinion

\begin{tabular}{|l|c|c|c|}
\hline \multicolumn{1}{|c|}{ Case } & Yes & $\begin{array}{c}\text { Somewhat } \\
\text { Yes }\end{array}$ & No \\
\hline $\begin{array}{l}\text { Increase the efficiency of care improvesthe quality } \\
\text { of patient care. }\end{array}$ & $100 \%$ & - & - \\
\hline $\begin{array}{l}\text { Needed for electronic record to easy access and } \\
\text { collect of patient information }\end{array}$ & $100 \%$ & - & - \\
\hline $\begin{array}{l}\text { Ministry of health should encourage and adapt the } \\
\text { methods to reduce the Diseases }\end{array}$ & $100 \%$ & - & - \\
\hline Currently, such PISIH system already using in Iraq & $15 \%$ & $10 \%$ & $75 \%$ \\
\hline $\begin{array}{l}\text { Uses of PISIH will be easy to use and access by } \\
\text { Hospital and researchers }\end{array}$ & $80 \%$ & $10 \%$ & $10 \%$ \\
\hline PISIH can use as repository of patient data & $100 \%$ & - & - \\
\hline PISIH can utilize to analyze the data & $90 \%$ & $10 \%$ & - \\
\hline
\end{tabular}

Table 2: Researchers Interested in Health Care Field

\begin{tabular}{|c|c|c|c|c|}
\hline Case & $\begin{array}{c}\text { Very } \\
\text { important }\end{array}$ & $\begin{array}{c}\text { Somewhat } \\
\text { important }\end{array}$ & Neutral & $\begin{array}{c}\text { Somewhat } \\
\text { unimportant }\end{array}$ \\
\hline $\begin{array}{l}\text { Nowadays, Researchers should } \\
\text { register to login to PISIH (Only } \\
\text { authorized users able to access) }\end{array}$ & $80 \%$ & $5 \%$ & $5 \%$ & $10 \%$ \\
\hline $\begin{array}{l}\text { Need to add more Patient } \\
\text { informationto current PISIH }\end{array}$ & $50 \%$ & $50 \%$ & - & - \\
\hline $\begin{array}{l}\text { Require more data resources for } \\
\text { Researchers in various fields of } \\
\text { science }\end{array}$ & $95 \%$ & $5 \%$ & - & - \\
\hline $\begin{array}{l}\text { Communication and share } \\
\text { information among different } \\
\text { institutions and organizations } \\
\text { yield developing their tasks. }\end{array}$ & $100 \%$ & - & - & - \\
\hline
\end{tabular}




\begin{tabular}{|l|c|c|c|c|}
\hline $\begin{array}{l}\text { Hospitals and Health institution } \\
\text { will heln to imnlement the PISIH }\end{array}$ & $75 \%$ & $15 \%$ & $5 \%$ & $5 \%$ \\
\hline $\begin{array}{l}\text { Researchers need more systems } \\
\text { in various fields to help them to } \\
\text { take decisions }\end{array}$ & $100 \%$ & - & - & - \\
\hline
\end{tabular}

The results encourage to develop a new such a proposed system to enhance the health care in my country.

\section{IMPLEMENTATION}

The implementing of [5] shows analysis results of potential sources of PISIH implementation with various difficulties.Linking Ministry of Health hospitals electronically unified channel, and creating an electronic health record for every citizen. One of big advantages of the system that the search can be done by name of hospital, diagnosis, date, personal information of patient, and the date of his death. Doctor can access a patient's record and update his observations. Windows Forms based on the .NET Framework used as interface to develop rich Windows applications.

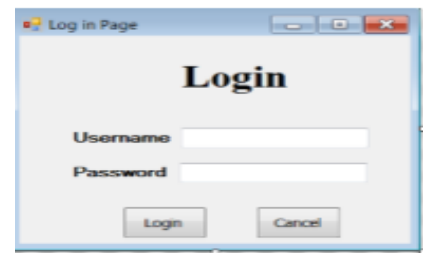

Fig 4:Login Page

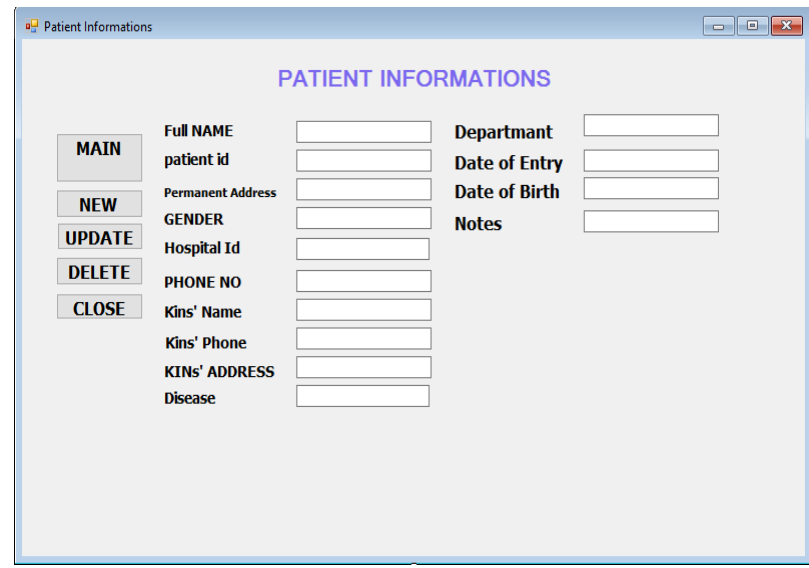

Fig 5: Required Patient Information

Administrator like will have complete control to the system, assign user name and password to employee Detail Recording to enter the information about the Admitted Patient shows in Figure 5 to specific Hospital or health centers, so by this they can enter in to their related page and he is managing the detail of Medicine, Test etc. to particular Patient.

Figure 6 gives the final report for the patient that will be stored in main database then appear as number of status in the terms of gender, locations,...etc.

Back end database stores all the information of all registered Researcher use web page belongs to the specific organization to get required information for that purpose.

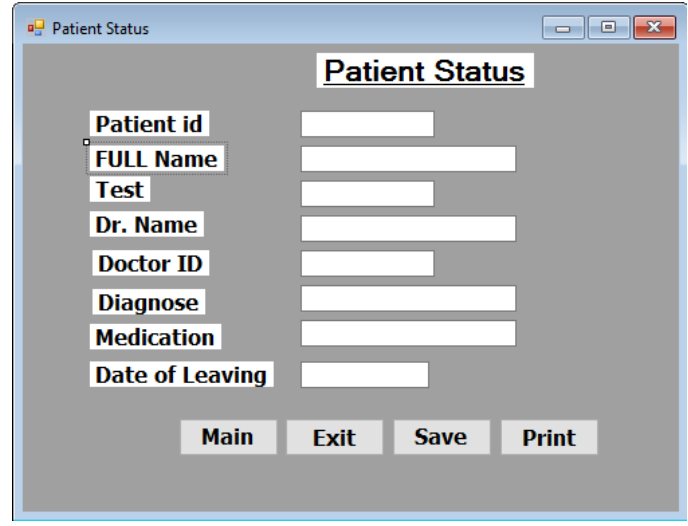

Fig 6: Patient Status Fields

Guarantee that its patients take required and suitable cure, Hospitals and clinics are predictable to preserve a continuous source of different critical items such as medications, treatment plans, immunization dates etc. This proposed system if implemented on a large scale by the Iraqi Ministry of Health on a wide range of countries will inevitably positive affect the health care and the prevention of many diseases. Products used: ASP.NET, C\# language, Visual Web Developer 2010 Express Edition and SQL Server 2008 Express Edition to get the page in figure 7, SQL Server Database provides security to penetrate databases .The engine to respond to all customer requests on the network. Predefined functions Stored Procedures, Triggers, Rules, User Defined Types, and processes Transactions and many other additions that have increased the strength and stability of this system.

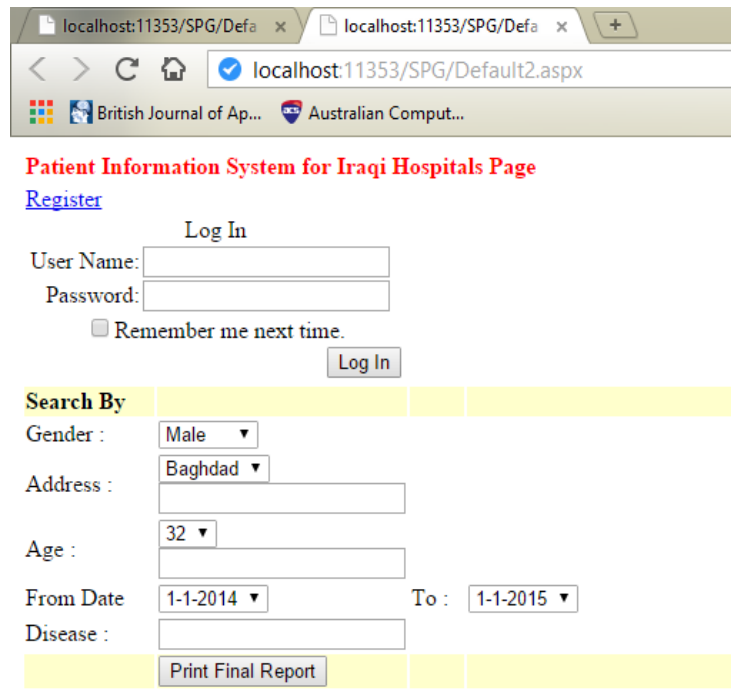

Fig 7: ASP Researcher Page

\section{CONCLUSION}

Develop PISIH system after implementing in real time also adapt new important health care system such as preventing pediatric medication errors, computer-based patient records, patient monitoring system,...et. All of those systems used by the Health organizations for investing in information technologies in developed countries [24], applying of it in health organization of Iraq will effect positively in the Health care. Proposed system epically designs for a large segment of researchers interested in the health care. Government should adopt electronic systems for electronic records to overcome the technological and social obstacles and telecommunications 
infrastructure, especially in developing countries, in addition to providing financial support for the implementation of electronic health records.

\section{REFERENCES}

[1] List of hospitals in Iraq.
"http://en.wikipedia.org/wiki/List_of_hospitals_in_Iraq".

[2] Dave Garets and Mike Davis, " Electronic Medical Records vs. Electronic Health Records: Yes, There Is a Difference" A HIMSS AnalyticsTM White Paper, Updated January 26, 2006.

[3] Prasad Jayaweera, JeewanieJayasinghe, LalWellakkage VajiraMalawaraarachchi, Samantha Liyanage "Clinics Management System (CMS) based on Patient Centered Process Ontology" Vol. 1, No. 1, Septem/ber 2006, pp. 40-39.

[4] Yola, Adamawa State- Nigeria, Oye, N. D, Monday Goji "HOSPITAL PATIENT DATABASE MANAGEMENT SYSTEM", An international journal of advanced computer technology, 2 (3), March2013.

[5] Ö Sagiroglu , "Implementation Difficulties of Hospital Information Systems" Information Technology Journal 5 (5):892-899, 2006 ISSN 1812-5638.

[6] Ma Kai-Christoph Hamborg1, Brigitte Vehse1, HansBernd Bludau2 " Questionnaire Based Usability Evaluation of Hospital Information Systems",www.ejise.com ,ISSN: 1566-6379.

[7] Martin Smits and Gert van der Pijl, "Developments in Hospital Management and Information Systems" Proceedings of the 32nd Hawaii International Conference on System Sciences - 1999.

[8] B. Likar and F. Pernu ss, "Registration of serial transverse sections of muscle fibers," Cytometry, vol. 37, no. 2, pp. 93-106, 1999.

[9] David Cella, $\mathrm{PhD},{ }^{*} \dagger$ Susan Yount, $\mathrm{PhD},{ }^{*} \dagger$ Nan Rothrock, $\mathrm{PhD},{ }^{*} \dagger$ Richard Gershon, $\mathrm{PhD},{ }^{*} \dagger$ Karon Cook, PhD,* Bryce Reeve, PhD, $\$$ Deborah Ader, $\mathrm{PhD}, \S$ James F. Fries, MD,II Bonnie Bruce, DrPH, MPH, RD, I and Mattias Rose, MD\|, on behalf of the PROMIS Cooperative Group "The Patient-Reported Outcomes Measurement Information System (PROMIS)" volume 45 on page 1008 ,May 2006--supplement 1.

[10] Harniss M, AmtmannD, Cook D, et al. Considerations for developing interfaces for collecting patient-reported outcomes that allow the inclusion of individuals with disabilities. Med Care. 2007;45 Supple 1:S48-S54.

[11] L. Leonard Hacker"Patient-controlled medical information system and method" US6988075 B1, US 09/525,244, Jan 17, 2006

[12] Joan S. Ash, PhD, MLS, Marc Berg, MD, PhD, and Enrico Coiera, MBBS, PhD "Some Unintended
Consequences of Information Technology in Health Care: The Nature of Patient Care Information Systemrelated Errors" 2004 Mar-Apr; 11(2): 104-112.

[13] David W. Bates, Atul A. Gawande ") Improving Safety with Information Technology, New EnglandJournal ofMedicine,348:2526-2534, 2003.

[14] Patel VL, Kushniruk AW. Understanding, navigating and communicating knowledge: issues and challenges. Methods Inf Med. 1998;37:460-70.

[15] By Syed Murtuza Hussain Bakshi\&Shakeel.M "A Study on Hospital Information System at a Tertiary Teaching Hospital" Global Journal of Computer Science and Technology Interdisciplinary (USA) Volume 12 Issue 10 Version 1.0 Year 2012.

[16] Miller, R. H., and I. Sim. "Physicians" use of electronic medical records: Barriers and solutions. Health Affairs" 23, no. 2 (March/April): 116-126, 2004.

[17] Motta, G.H.B., and Furuie, S.S. (2003) "A Contextual Role-Based Access Control Authorization Model for Electronic Patient Record", IEEE Transactions on Information Technology in Biomedicine, vol.7, no.3.

[18] Blobel, B. (2004) "Authorization and Access control for Electronic Health Record Systems," International Journal of Medical Informatics", vol. 73, pp 251-257.

[19] E. Bertino, J. Cramption, and F. Paci. "Access control and authorization constraints for ws-bpel". In IEEE International Conference on Web Services (ICWS), pp. 275-284, Chicago, Illinois, USA, 2006.

[20] E. Bertino, A. C. Squicciarini, and D. Mevi. "A finegrained access control model for web services".In IEEE International Conference on Services Computing, pp. 33-40, Shanghai, China, September 2004.

[21] D. D. He and J. Yang. A policy driven authorization control framework for business collaboration. In IEEE SCW, pp. 17-24, Salt Lake City, Utah, USA, July 2007.

[22] James R. Fricton, DDS, MS; Diane Davies, MD "Personal Health Records to Improve Health Information Exchange and Patient Safety". In: Henriksen K, Battles JB, Keyes MA, Grady ML, eds. Advances in Patient Safety: New Directions and Alternative Approaches. Vol. 4. Technology and Medication Safety. Rockville, MD: Agency for Healthcare Research and Quality; 2008.

[23] Heine RP, Maddox EN. "Hospital management reform: A step to healthcare reform". J Manag Mark Res. 31 march 2013.

[24] Vital wave consulting HIS, "Health Information Systems in Developing countries", A Landscape Analysis, May 2009. 